\title{
Cadeias Produtivas de Leite: um estudo comparativo entre duas realidades
}

\author{
Milk production chains: a comparative study between two realities
}

\author{
Nilda Souza Oliveira', Theophilo Alves Souza Filho², Mariluce Paes-de-Souza ${ }^{3}$, Fabiana Rodrigues Riva ${ }^{4}$ \\ 1, 2, 3 Universidade Federal de Rondonia
}

\begin{abstract}
Resumo
A presente pesquisa teve como objetivo identificar a competitividade da produção primária da cadeia produtiva de leite do município de Jaru-RO, comparada à de Patos de Minas-MG. Esse estudo baseou-se na proposta de competitividade apresentada por Ferraz, et al., para os quais a competitividade deve ser analisada partindo-se da dinâmica do mercado em que ocorre a concorrência, pois não apenas os fatores internos às organizações são imprescindíveis para análise da competitividade, mas ainda os fatores estruturais e os sistêmicos. Quanto ao método, utilizou-se a abordagem qualitativa, cujo procedimento foi o estudo de campo. Para a coleta de dados primários, foi utilizado como instrumento formulário de entrevistas estruturado, aplicados a uma amostra de produtores de leite dos municípios estudados. Para avaliação quanto ao nível de competitividade, os fatores avaliados foram mensurados utilizando-se o método da média ponderada. Com base na análise de 32 fatores de competitividade, o resultado da pesquisa demonstrou que o município de Jaru possui um nível de competitividade regular, enquanto o município de Patos de Minas apresenta nível de competitividade mais alto. Constatou-se ainda que em Jaru a atividade é pouco tecnificada, o que resulta, como consequência, baixo desempenho. A análise dos fatores externos ao empreendimento, relevantes para o sucesso competitivo, também apresentou baixa avaliação no nível de competitividade. Assim, na perspectiva de aprimoramento desse sistema, a Cadeia Produtiva de Leite em Jaru-RO necessita desenvolver fatores que inferem nas vantagens competitivas desse segmento, em vista da obtenção de um melhor desempenho na produção e no atendimento às exigências cada vez maiores do mercado consumidor. Palavras-chave:
\end{abstract}

\begin{abstract}
This research aimed to identify the primary's production competitivity level of milk chain production in the city of Jaru-RO, compared to Patos-MG. This study was based on the proposed competitiveness by Ferraz et al., for which competition should be analyzed starting from the dynamics of the market in which competition occurs, since not only the internal factors are essential for organizations to analyze the competitiveness, but also the structural and systemic factors. As to the method, the research was based on a qualitative approach, whose procedure was the field study. For primary data collection was used an instrument in the form of structured interviews applied to a sample of milk producers in the cities studied. To assess the competitiveness level, the evaluated factors were measured using the weighted average method. Based on analysis of 32 competitiveness factors, the result of research showed that the Jaru's city has a regular level of competitiveness, while the city of Patos has seen a high level of competitiveness. It was further observed in this research activity is in Jaru technified bit, because it has a flock of low genetic potential in milk production, supplementary feeding deficiency in the herd, poor training of producers, which results generally in low performance. The analysis of enterprise external factors, relevant to the competitive success of this segment also have low evaluation level of competitiveness. Thus, in view of enhancing this system, the Jaru's milk chain production needs to develop several factors competitive advantages that emerge in this segment, in view of obtaining a better performance in production and in meeting the increasing demands of the consumer market.
\end{abstract}

Keywords: . . 


\section{INTRODUÇÃO}

Há pouco tempo, a concorrência não era tão percebida em muitos países e em vários setores. Com o processo de globalização e a abertura dos mercados nacionais, houve uma profunda mudança na estrutura econômica de diversos segmentos econômicos nos países, gerando um ambiente comercial mais competitivo e volátil, no qual as organizações passaram a enfrentar a competição internacional em larga escala, como se observa com o competidor China.

As transformações ocorridas na Cadeia Produtiva de Leite no Brasil no início da década de 1990 é um exemplo nítido dos impactos que as forças competitivas exercem sobre o mercado. Segundo Nogueira, et al. (2006) a cadeia produtiva de leite é que mais vem apresentando mudanças nos últimos anos, sendo que as principais causas referem-se não apenas à desregulamentação do mercado de leite a partir de 1991 implementada pelo governo brasileiro, mas principalmente a maior abertura da economia brasileira para o mercado internacional, que gerou uma acirrada concorrência com os produtos importados.

Verifica-se assim que o crescimento da produção de leite no Brasil nas últimas décadas se deve, sobretudo, à pressão do mercado competitivo. A preocupação com a competitividade passa então a orientar de forma crescente os agentes da cadeia produtiva do leite no Brasil, desde as agroindústrias aos produtores rurais, que buscam qualidade, produtividade, redução de custos, integração e alianças estratégicas, como forma de enfrentar a competição no mercado interno e de estarem capacitados para disputar o mercado externo.

Em vista desses fatores, a produção de leite vem se destacando no agronegócio brasileiro e apresentando crescimento considerável nos últimos anos. Dentre os principais países produtores de leite, o Brasil a partir de 2009 aparece como o $5^{\circ}$ maior produtor do mundo, cuja produção alcançou mais de 29 milhões de toneladas naquele ano.

Segundo Alvim (2009), o segmento da produção primária da cadeia produtiva de leite, os ganhos da produtividade é o resultado da adoção de tecnologia que melhoraram a eficiência do uso dos fatores de produção, como o melhoramento da genética do rebanho, da alimentação e da saúde dos animais. Apesar da intensa modernização, Nogueira, et al. (2006) afirmam que a produção leiteira no Brasil ainda é caracterizada pela baixa adoção de tecnologia, embora existam já um número significativo de produtores altamente tecnificados.

O baixo nível tecnológico na produção de leite no Brasil é uma das características que pode ser observada também em Rondônia, em que o agronegócio leite tem um desempenho significativo na economia do Estado. Com o expressivo crescimento na produção de leite nos últimos anos, o Estado vem destacando-se como um dos maiores produtores de leite em volume no Brasil e o primeiro maior produtor da região Norte.

O município de Jaru destaca-se como maior produtor de leite em Rondônia, cuja produção de 75,49 milhões de litros em 2009 representou mais de 10\% da produção estadual. Na última pesquisa da pecuária municipal de 2009 realizada pelo IBGE, Jaru aparece no ranking entre os 20 maiores produtores de leite no Brasil, ocupando o vigésimo lugar.

Entretanto, apesar do crescente desempenho na produção em Rondônia e de inúmeras tecnologias disponíveis ao produtor de leite, Scheidt (2008) observa que há poucos investimentos nesse segmento, o que se reflete na baixa produtividade do rebanho leiteiro do Estado. Isso pode ser constatado a partir dos dados mostrados na figura 1 - constante do anexo I, que compara Jaru ao município de Patos de Minas, em Minas Gerais, segundo maior município produtor de leite no Brasil e o maior produtor de leite do estado de Minas Gerais.

Notam-se importantes diferenças na produção entre as duas bacias leiterias, sinalizadas principalmente pelo desempenho litro/vaca/ano, pois enquanto a produtividade média no município de Patos de Minas em 2009 foi de 2.271 litros/vaca/ano, em Jaru, maior produtor de Rondônia, a produtividade no mesmo período foi de 810 litros/vaca/ano.

Assim, observa-se que apesar das crescentes mudanças que ocorrem em um mercado globalizado e altamente competitivo forçarem os empreendimentos rurais, assim como impulsionam as empresas de outros setores a se adequarem aos novos padrões estabelecidos a incrementarem seus negócios, fatores de competitividade, como o uso da tecnologia e manejo ainda é deficiente na produção de leite o estado de Rondônia. 
Diante do contexto apresentado sobre a produção de leite no estado de Rondônia, o que motivou a pesquisa é saber o nível de competitividade do segmento da produção primária da Cadeia Produtiva de Leite no município de Jaru, em Rondônia, em relação ao de Patos de Minas-MG. Portanto, o objetivo do estudo foi comparar o nível de competitividade da produção primária de leite entre duas importantes bacias leiteiras no senário nacional.

\section{DESENVOLVIMENTO DO TRABALHO}

\section{I A QUESTÃO SOBRE A COMPETITIVIDADE}

$\mathrm{Na}$ literatura que trata sobre competitividade verifica-se que não há um satisfatória consenso ou explicitação do seu respectivo conteúdo, quer em termos teóricos, quer em termos operacionais, segundo afirmam Alves e Ferreira (2009).

De acordo com Poter (1993), para as empresas a competitividade poderia significar a capacidade de competir em mercados mundiais com uma estratégia global, enquanto para as nações a competitividade seria uma balança comercial positiva e, ainda, para alguns economistas ela pode significar baixo custo de mão de obra, associado às taxas de câmbio.

A partir desse exemplo é possível observar que falta um consenso quanto à definição do termo competitividade, assim como a metodologia mais adequada de se avaliar a competitividade de uma empresa ou um setor.

Diante de um complexo processo-evolutivo e dinâmico no estudo sobre esses temas, o entendimento e consenso sobre o assunto torna-se extremamente difícil, conforme enfatiza Teixeira (2005, p. 746) ao afirmar que "[...] embora competitividade industrial seja uma expressão bastante difundida nas análises e discursos atuais, o entendimento preciso dos elementos que a definem não é objeto de consenso".

Nesse contexto, o diagnóstico da competitividade de um determinado setor requer que, inicialmente, se delineie o debate teórico que resulta na formulação de diferentes conceitos de competitividade. A partir desse debate, buscar-se-á identificar a metodologia mais adequada que compreenda a competitividade na sistemática do agronegócio, visando assim cumprir os objetivos propostos neste estudo.

Abordagem tradicional sobre a competitividade

As raízes das discussões sobre o termo competitividade são multidisciplinares, existindo diversas acepções quanto à sua abordagem tanto na literatura nacional quanto na internacional, seja no que se refere à competitividade de empresas, setores econômicos, ou até mesmo de países.

Em termos históricos, a discussão sobre os determinantes de competitividade tem origem nos trabalhos dos economistas clássicos Adam Smith e David Ricardo, para os quais as vantagens competitivas das nações eram atribuídas ao diferencial de custo de produção.

Queiroz (2005) ressalta que a Teoria das Vantagens Comparativas de Ricardo, assim como a Teoria das Vantagens Absolutas de Smith, baseou-se principalmente no diferencial dado pelos custos de produção ou nas diferenças de produtividade entre as nações, os quais serviram como referencial para a construção de outras teorias, tais como a das Dotações Fatoriais de Ohlim, Heckscher e Paul Samuelson.

Contudo, há diversas críticas quanto a essa concepção clássica sobre a competitividade. Segundo Porter (1993), a vantagem comparativa que se origina na disponibilidade de recursos como mão de obra, recursos naturais e de capital não determina a prosperidade das empresas, visto que se tornara de ampla disponibilidade devido à globalização da competição e pelo poder da tecnologia.

Por sua vez, Hunt e Morgan (apud Caldeira e Siqueira, 2009) apontam que a competitividade na concepção da teoria econômica neoclássica dá-se num regime de concorrência perfeita, em que os recursos são homogêneos e perfeitamente flexíveis. Neste mesmo prisma, Caldeira e Siqueira (2009) observam que na concepção neoclássica todos os agentes possuem informações perfeitas a respeito do preço dos produtos, da quantidade produzida, do preço dos insumos e o mercado ajusta-se de forma imediata. A abordagem neoclássica, desse modo, não considera a possibilidade de existir uma dinâmica competitiva que não seja baseada apenas em preço e quantidade.

Diante dessas considerações, observa-se que é consenso entre diversos autores que, para se avaliar a competitividade de países, setores e empresas, atualmente não se deve utilizar de teorias que se 
baseiam apenas nos fatores de produção, tal como a Teoria das Vantagens Comparativas, uma vez que esses fatores compõem apenas um dos pilares da competitividade (SILVA NETO e PIZZOLATO, 2001).

A concepção dinâmica sobre a competitividade à luz da Teoria Neo-Schumpeteriana

Dentro de uma abordagem dinâmica sobre a competitividade, os autores tomam como base a teoria econômica de Schumpeter que, ao tratar da dinâmica da economia capitalista, descreve uma nova dialética para o capitalismo, distanciando-se dos métodos e análises estáticos da escola clássica (TAVARES, et al., 2009).

A dinâmica da economia, na visão de Schumpeter, advém da introdução de inovações pelos empresários, ou seja, de novas combinações dos fatores de produção disponíveis. De acordo com Tavares, et al. (2009), a introdução dessas inovações é empreendida do ponto de vista de competitividade, visto que:

[...] as vantagens comparativas tradicionais, como a dotação de fatores e recursos naturais, assim como a mão de obra a baixo custo (vantagens dadas, estáticas, constantes), vem cedendo lugar à informação e à densidade tecnológica, fazendo com que as vantagens comparativas tendam a se tornar vantagens competitivas (vantagens construídas, dinâmicas (TAVARES, et al., 2009, p. 2).

Na percepção de Tavares, et al. (2009), os preceitos Schumpeterianos que explicam a dinâmica do processo de crescimento e/ou desenvolvimento econômico capitalista continuam vivos com a escola neo-schumpeteriana. Para essa corrente, a inovação e o progresso tecnológico continuam sendo variáveis endógenas que explicam a mudança e a dinâmica da economia.

Dessa forma, ao contrário da corrente tradicional clássica, que tinha como questão fundamental a ideia de equilíbrio no longo prazo, associada à capacidade de pouca ou nenhuma mudança nas estruturas de mercado pelas ações das empresas, a corrente neo-schumpeteriana busca outros caminhos não determinísticos.

Segundo Lima (2007), a introdução de conceitos evolucionistas na análise das firmas e do processo de concorrência, associada à inovação tecnológica, e as estratégias da empresa, que passam a ser os elementos endógenos que irão influenciar e até mudar as estruturas de mercado, trazem uma nova visão no estudo da concorrência e da competitividade.

Essa nova forma de ver o mercado, em constantes mudanças, evidencia suas premissas, pois, na visão dessa corrente, a empresa e o ambiente então em permanente troca, fazendo com que as mudanças na estrutura tecnoeconômica existentes e nas estruturas organizacionais sejam constantes (LIMA, 2007).

Desse modo, a noção de competitividade baseada na corrente teórica neo-schumpeteriana parte da concepção de como ocorre a concorrência. Assim, Possas (1996) destaca que:

Se o "locus" da concorrência é, por definição, o mercado, seu agente é, naturalmente, a empresa, mediante a formulação e execução de estratégias competitivas. No entanto, como competitividade pressupõe capacidade inovativa ("lato sensu"), as condições específicas (tecnológicas, produtivas e de mercado) da indústria considerada e do ambiente econômico num sentido mais amplo (externalidades físicas, sociais, técnico-científicas; condições institucionais; aparato regulatório) são decisivas para que as empresas desenvolvam seu potencial competitivo, naturalmente diferenciado e assimétrico (POSSAS, 1996, p. 73).

A partir dessa abordagem, observada por Possas, a competitividade ganha complexidade e passa a envolver não apenas fatores endógenos, tais como a inovação e a estratégia adotada pela empresa, mas ainda aqueles inerentes ao ambiente concorrencial (estrutura) e político social (sistêmico).

Fatores determinantes da competitividade - Made in Brazil

No universo empresarial, há sem dúvida um conjunto de fatores que atua como determinantes da competitividade, os quais transcendem o nível da firma, estando relacionados ainda à estrutura da indústria e do mercado e ao sistema produtivo como um todo. Nessa perspectiva, Ferraz, et al. (1997), seguindo a corrente de autores neo-schumpeterianos, abordam a competitividade numa visão dinâmica, a qual permite que estudiosos do assunto vislumbrem um grande número de fatores que interferem na empresa, no ramo industrial, ou mesmo na competitividade de um país.

Na obra "Made in Brazil", Ferraz, et al. (1997) definem a competitividade como:

a capacidade da empresa formular e implementar estratégias concorrenciais, que lhe permitam ampliar ou conservar, de forma duradoura, uma posição sustentável do mercado. Esta visão se diferencia de modo significativo das abordagens convencionais na medida em que busca na dinâmica do 
processo de concorrência o referencial para avaliação da competitividade (FERRAZ, et al., 1997:3, grifos do autor).

Segundo o autor, a partir dessa perspectiva dinâmica, o desempenho no mercado e a eficiência produtiva decorrem da capacitação acumulada pelas firmas que, por sua vez, representam as estratégias competitivas adotadas em função de suas percepções quanto ao processo concorrencial e ao ambiente econômico em que se inserem. Nessa mesma visão, Kupfer (1991) descreve a competitividade como a função de adequação das estratégias das empresas individuais ao padrão de concorrência vigente no mercado específico.

Em vista disso, a identificação dos fatores relevantes para o sucesso competitivo, que variam de acordo com o padrão de concorrência vigente em cada setor, bem como a verificação de sua importância setorial no presente e o que se pode esperar no futuro próximo, é fundamental para avaliar a capacidade da empresa em formular e implementar estratégias (FERRAZ, et al., 1997)

Com o objetivo de promover o entendimento sobre os fatores determinantes de competitividade, Ferraz, et al. (1997) propõem que a análise da competitividade deve ser centrada em três grupos, que abrangem diversos aspectos que vão desde os internos às empresas até aqueles que se referem à inter-relação do país com o mundo. Esses três grupos de fatores determinantes de competitividade são: empresariais (internos à empresa), estruturais (referente à indústria ou complexo industrial) e sistêmicos.

O grupo de fatores empresariais é constituído pela gestão, inovação, recursos humanos e produção. Esses fatores são aqueles sobre os quais a empresa detém poder de decisão e podem ser controlados ou modificados por meio de condutas ativas assumidas, correspondendo as variáveis no processo decisório.

Quanto aos fatores estruturais, esses são constituídos pelos fatores de mercado, da configuração da indústria e do regime de incentivos e regulação da concorrência. As maneiras como as empresas se relacionam e como ocorre a dinâmica da concorrência formam a principal parte dos fatores estruturais. A capacidade de intervenção da empresa sobre esses fatores é limitada pela mediação do processo de concorrência, estando por isso apenas parcialmente sob sua área de influência.

Já os fatores sistêmicos representam externalidades à empresa e sobre os quais ela detém escassa ou nenhuma possibilidade de intervir, mas que constituem parâmetros do processo decisório. São formados por fatores legal-regulatórios, infraestruturais, sociais, político-institucionais, internacionais e macroeconômicos.

De modo geral, segundo Ferraz, et al. (1997), os fatores empresariais e sistêmicos apresentam caráter mais genérico em se tratando das formas e intensidades com que influenciam a competitividade nos diversos setores industriais. Já os fatores estruturais, ao contrário dos demais, apresentam um nítido caráter setor-específico, o que reflete mais diretamente as peculiaridades dos padrões de concorrência em cada indústria.

Desse modo, para se atingir os objetivos propostos para esse estudo entende-se que a abordagem que melhor abrangeria a complexidade do sistema agroindustrial, objeto desse estudo, é a análise proposta por Ferraz, et al. (1997). Essa abordagem, ao considerar que todos os fatores (empresariais, estruturais e sistêmicos) são importantes para determinar a competitividade, acaba por deixar ampla a própria relação de itens pertencentes a cada grupo, mostrando que nenhuma classificação isoladamente iria abranger a complexidade que envolve a dinâmica econômica do agronegócio.

2.2 Aspectos sobre os empreendimentos rurais no agronegócio brasileiro

Tendo em vista que o ambiente econômico e social em que o agronegócio está inserido se tornou cada vez mais complexo e diversificado, o que anteriormente era entendido como exploração econômica de propriedades rurais isoladas é parte de um amplo espectro de inter-relações e interdependências produtivas, tecnológicas e mercadológicas (CALLADO e CALLADO, 2009).

As propriedades rurais agora são entendidas desse modo como organizações agroindustriais que, em um mercado altamente competitivo, devem se adequar aos novos padrões estabelecidos e incrementar seus negócios. Para Nantes e Scarpelli (2009), devido à busca de competitividade, é necessário os empreendimentos rurais conhecerem as alternativas estratégicas que são mais adequadas para integrar-se às novas exigências do agronegócio.

$\mathrm{O}$ uso da tecnologia no processo produtivo dos empreendimentos rurais torna-se, portanto, um fator necessário. Em virtude do grande nível de exigência dos mercados, Araújo (2009) afirma que a adoção de tecnologia se apresenta como uma necessidade para a permanência da atividade, auferindo ganhos na produtividade e na escala aos produtores. 
No Brasil, no entanto, ainda há grande resistência do produtor rural na adoção de inovação tecnológica, o qual é comum à grande parte dos empreendimentos rurais. Segundo Nantes e Scarpelli (2009), o baixo emprego de tecnologia é comum principalmente aos pequenos produtores rurais, os quais apresentam produtividade inferior à média devido à baixa ou má utilização da tecnologia disponível, seja por falta de capital, resistência à adoção de novas tecnologias ou até mesmo por falta de conhecimento.

Aliado a isso, Nantes e Scarpelli (2009) ressaltam ainda que a assistência técnica no Brasil - que contribui com a orientação aos produtores quanto à adoção inovações de tecnológicas na produção -, apesar de estar disponível para grande parte dos produtores rurais, é incapaz de atender às necessidades do agricultor, pois nem sempre são compreendidas ou implementadas devido às condições de cada produtor.

Quanto às políticas de crédito, essas vêm a se torna um importante instrumento de modernização da agricultura ao possibilitar a incorporação de maquinaria e insumos à produção. Entretanto, no Brasil, apesar de existirem recursos institucionais obrigatórios, esses ainda não atingem seus objetivos, ou seja, são insuficientes, burocráticos quanto à concessão, com alta taxa de juros e condições de pagamentos inadequados, não atendendo de forma eficiente a muitos pequenos e médios produtores rurais (NANTES e SCARPELLI, 2009).

Apesar das dificuldades apresentadas, em virtude das crescentes exigências do mercado consumidor quanto à qualidade, preço, disponibilidade, dentre outros, os produtores devem elaborar estratégias de viabilização do negócio para amenizar o impacto dessas exigências. Assim, independentemente do porte do empreendimento rural, as alterações e exigências do mercado vêm impondo a todos os elos da cadeia produtiva significativas mudanças para se manterem na cadeia e obterem sucesso nos negócios.

Características da Produção de Leite em Rondônia e no Município de Jaru/RO

Com um crescimento significativo, Rondônia vem destacando-se como um dos maiores produtores de leite no Brasil e o primeiro maior produtor da região Norte. Para Paes de Souza (2007), a performance apresentada na produção no Estado é explicada em virtude dos baixos custos de produção prevalecentes, as condições favoráveis de clima e solo, mercado direcionado para a industrialização e principalmente a baixa ou nenhum emprego de insumos, sendo uma atividade eminentemente voltada à agricultura familiar.

O município de Jaru é o maior produtor de leite do Estado, cuja produção de 75,49 milhões de litros em 2009 representou mais de $10 \%$ da produção estadual. Na última pesquisa da pecuária municipal de 2009 realizada pelo IBGE, Jaru aparece no ranking dos 20 maiores produtores de leite no Brasil, ocupando o vigésimo lugar.

No que tange à produtividade, Rondônia apresentou em 2009 uma produtividade de 714 litros/ vaca/ano, sendo muito inferior à média do Brasil de 1.297 litros/vaca/ano. Logo, a produtividade média de leite em Rondônia encontra-se $45 \%$ inferior à média nacional. O município de Jaru, por sua vez, apresenta uma média de produtividade de 810 litros/vaca/ano, o que mostra ser 13,4\% maior que a média estadual e 37,5\% menor que a média nacional.

Portanto, apesar de o Estado ser um grande produtor de leite em volume e apresentar um crescente desempenho na produção, ainda assim sua produtividade é considerada muito baixa. De acordo com Paes-de-Souza (2007), um dos problemas da pecuária de leite em Rondônia está vinculado a pouca especialização do rebanho para a produção de leite e à baixa frequência de utilização de suplementos alimentares pelos produtores.

Scheidt (2008) observa ainda que em Rondônia, apesar de inúmeras tecnologias disponíveis ao produtor de leite, há poucos investimentos nesse segmento, que ocorre tanto pela falta de interesse do produtor em melhorar sua produção quanto pela baixa capacidade de investimento que este possui.

Desse modo, tendo em vista que as condições climáticas de Rondônia não são tão boas para animais especializados na produção de leite, verifica-se que é fundamental o suporte do Estado, mediante geração e difusão de tecnologias apropriadas para o pleno desenvolvimento da pecuária de leite. Contudo, não se deve perder de vista a participação da indústria de laticínios no processo de modernização da pecuária de Rondônia.

Características da Produção de Leite em Minas Gerais e no Município de Patos de Minas/MG

A produção de leite em Minas Gerais configura-se como uma das atividades mais importantes para a economia do Estado. Historicamente, Minas Gerais tem grande contribuição na produção 
nacional, respondendo por cerca de $30 \%$ da produção de leite do Brasil nos últimos anos.

Com 853 municípios, o Estado de Minas Gerais está dividido em 12 mesorregiões. Dentre elas, o Triângulo Mineiro/Alto Paranaíba destaca-se como maior produtora de leite, cuja produção em 2008 foi cerca de 1,8 bilhão de litros, seguida pelo Sul/Sudoeste de Minas com 1,3 bilhão de litros.

Vale destacar que, no ranking dos 20 maiores produtores de leite no Brasil em 2009, o município de Patos de Minas, localizado na microrregião de Patos de Minas, mesorregião do Triangulo Mineiro/ Ato Paranaíba, foi avaliado como o segundo maior produtor de leite brasileiro, sendo o primeiro maior produtor do Estado. Segundo o IBGE (2010), a produção do município em 2009 foi de 137,5 milhões de litros naquele ano, correspondendo a $1,73 \%$ da produção estadual. Em termos de produtividade, o município apresenta uma produtividade de 2.271 litro/vaca/ano.

De acordo com Galinari, et al. (2002), Minas Gerais conta com produtores mais especializados, que têm contribuído para a melhoria da produtividade, e consequentemente o aumento da produção em praticamente todas as microrregiões mineiras. Segundo o autor, a melhoria significativa da produtividade está relacionada à adoção de tecnologias, como silagem, ordenha mecânica, resfriamento, granelização e melhoria genética do rebanho.

Entretanto, uma característica evidente da produção leiteira no Brasil e que se repete em Minas Gerais é a heterogeneidade dos produtores. Assim, de acordo com Gomes (2006) não é difícil encontrar numa mesma microrregião desde produtores especializados até pequenos produtores sazonais que fazem da atividade leiteira uma atividade complementar.

Desse modo, Galinari, et al. (2002) ressalta que apesar do destaque na produção de leite em Minas Gerais, a grande heterogeneidade da pecuária leiteira no estado, assim como no Brasil, coloca grandes desafios aos gestores públicos e agentes privados (notadamente a indústria de laticínios) na elaboração e implementação de políticas de âmbito regional voltadas para a modernização e redução das desigualdades intrassetoriais.

\section{MATERIAL E MÉTODO}

Segundo seu objetivo, a presente pesquisa buscou identificar o nível de competitividade do segmento da produção primária da cadeia produtiva de leite do município de Jaru - RO, comparando-a com a de Patos de Minas-MG. Para esse estudo, utilizou-se a análise de competitividade proposta por Ferraz, et al. (1997), segundo os fatores determinantes de competitividade, ou seja, os fatores empresarias, estruturais e sistêmicos, os quais foram adaptados ao segmento da produção e leite.

Para aprofundamento na análise quanto aos fatores de competitividade da produção rural de leite de Jaru - RO e de Patos de Minas-MG, bem como entender como esses fatores se relacionam entre si, utilizou-se na pesquisa a abordagem qualitativa, pois de acordo com Richardson (2007, p. 80) "Os estudos que empregam uma metodologia qualitativa podem descrever a complexidade de determinado problema, analisar a interação de certas variáveis, compreender e classificar processos dinâmicos vividos por grupos sociais [...]".

Quanto ao delineamento, a presente pesquisas caracteriza-se pelo tipo exploratória e descritiva. Nesse estudo foi utilizado como procedimento o estudo de campo, tendo em vista que a adoção desse procedimento visa dar maior profundidade ao problema proposto na pesquisa e às variáveis mensuradas.

Para análise dos fatores de competitividade da produção de leite em Jaru e em Patos de Minas, o presente estudo utilizou-se de dados primários, tendo como instrumento de coleta o formulário estruturado, com perguntas abertas e fechadas, os quais foram aplicados em forma de entrevista a uma amostra de produtores dos municípios de Jaru-RO e Patos de Minas-MG, no período de julho e agosto de 2011.

Para definição da amostra em cada um desses municípios, calculada a partir da fórmula apresentada por Silva, et al. (1997), consideraram-se as limitações naturais de distância dos municípios, a distância entre os produtores em cada linha, os quais estão dispersos geograficamente, e o difícil acesso das linhas. Em vista desses fatores, trabalhou-se nessa pesquisa um nível de confiança de $92 \%$ e erro de $8 \%$, que equivale para cada um dos municípios a uma amostra de 113 produtores, conforme apresentado na Figura 2. 
Para avaliação quanto ao nível de competitividade da produção rural de leite do município de Jaru, os fatores avaliados foram mensurados utilizando-se o método da média ponderada. Os resultados dos fatores analisados foram trabalhados numa escala de 0 a 10, figura 3 , para melhor compreensão do nível de competitividade de cada item, sendo avaliados da seguinte forma:

\section{RESULTADOS E DISCUSSÃO}

Para obter o nível de competitividade produção de leite de Jaru-RO e Patos de Minas-MG, buscou-se primeiramente sintetizar e mensurar o nível dos principais fatores determinantes de competitividade segundo os três conjuntos de fatores (empresarias, estruturais e sistêmicos), conforme apresentado na Figura 4.

Dos 32 fatores de competitividade da produção de leite analisados, nota-se na Figura 4 que dentre as médias apresentadas pelos produtores de Jaru, $9(28 \%)$ dos respondentes foram avaliados como muito baixo, $8(25 \%)$ como baixo e $8(25 \%)$ regular. Apenas $7(22 \%)$ foram avaliados como bom ou muito bom.

Destacam-se, portanto, dentre os fatores de competitividade da produção de Jaru, comparados com de Patos de Minas: o volume da produção de leite nas águas; a utilização da rotação de pastagem para o rebanho; os cuidados com medicamentos e vacinas para controle de doenças do rebanho; a avaliação dos produtores quanto às taxas de juros para financiamento; e a infraestrutura de comunicação e energia elétrica.

No que se refere à média do preço pago pelo litro de leite, apesar dos produtores de Jaru receberem um valor que corresponde a $78 \%$ do preço recebido pelos produtores de Patos de Minas, o que corresponde a um nível alto na ponderação, é importante observar que segundo a avaliação dos produtores o valor recebido foi considerado muito baixo. Esse fator, segundo observado na pesquisa de campo, tem grandes reflexos no processo produtivo, visto que muitos produtores se mostraram desestimulados em investir na produção ou mesmo permanecer na atividade em virtude do valor recebido.

Relevante ressaltar, contudo, que a rentabilidade somente vem com economia de escala, e mesmo não sendo pago um valor considerado bom pelos produtores para o leite, o aumento da produtividade por vaca/leite/dia aumentaria consequentemente a produção, diluindo os custos fixos, e torna mais rentável a atividade.

Para o aumento da produtividade, e consequentemente da produção, é necessário o uso de tecnologias no processo produtivo. Destaca-se nesse contexto a afirmação de Araújo (2009) em que, segundo o autor, a adoção de tecnologia se apresenta como uma necessidade para a permanência da atividade, auferindo ganhos na produtividade e na escala aos produtores. Assim, considerando que o processo de inovação tecnológica tem sua função dinamizadora da concorrência no interior de uma cadeia de produção, observa-se ainda na tabela 1 que aspectos de inovação tecnológica como melhoramento genético e alimentação do rebanho ainda são muito deficientes na produção de leite de Jaru.

Segundo a Embrapa (2009), as vacas tratadas no campo experimental de Porto Velho, da Embrapa de Rondônia, produzem em média 18 litros de leite por dia, e segundo se observa na figura 5, a média da produtividade em Jaru é de 3,66 litros/vaca/dia, enquanto a de Patos de Minas, que apresenta melhores índices de tecnologia, é de 10,92 litro/vaca/dia, quase 3 (três) vezes a produtividade média de Jaru.

O resultado do baixo nível de inovação tecnológica quanto à alimentação e melhoramento genético do rebanho observados em Jaru pode ser verificado ainda no que se refere à produtividade por hectare. Em relação a esse fator, verifica-se que a produtividade por hectare em Jaru é de 1,81 litros/ha, enquanto em Patos de Minas é de 8,60 litros/ha, ou seja, a produtividade por hectare em Jaru representa apenas $28 \%$ da apresentada em Patos de Minas.

Destaca-se ainda na análise quanto ao nível de competitividade da produção de leite em Jaru a percepção dos produtores quanto ao ambiente concorrencial. De acordo com Ferraz, et al. (1997) e Kupfer (1991), o desempenho no mercado e a eficiência produtiva representam as estratégias competitivas adotadas pelas empresas em função de suas percepções quanto ao processo concorrencial vigente no mercado específico. Em vista disso, observa-se na tabela 1 que os produtores de Jaru têm a percepção quase nula em relação ao nível de concorrência do setor, enquanto os produtores de Patos 
de Minas têm, apesar de um nível baixo, alguma percepção de concorrência entre os produtores, que segundo os pesquisados refletem sobretudo no preço pago pelo produto.

Esse fator pode revelar-se como uma variável relevante no que tange às estratégias competitivas dos produtores de leite, pois nota-se que, além do baixo nível de adoção de inovações tecnológicas, há um baixo nível de especialização entre produtores de Jaru.

Desse modo, apesar do nível de capacitação dos produtores e da mão de obra contratada de Patos de Minas e de Jaru ser muito baixo, observa-se que em Patos de Minas os produtores procuram conhecimentos sobre o processo de produção de leite por outras fontes de informações além dos cursos e treinamento, representando como muito alto o acesso às informações dos produtores desse município. Em Jaru, por sua vez, avaliou-se como regular o acesso às informações, visto que muitos produtores não têm o interesse em buscar novas informações sobre o processo de produção de leite.

Um dos fatores determinantes de competitividade estrutural que pode vir a estimular os produtores e a desenvolver a atividade refere-se aos programas de incentivo à produção de leite, como o Programa de Pecuária Leiteira - ProLeite, desenvolvidos no estado de Rondônia, e o Minas Leite, no estado de Minas Gerais, o quais, segundo Ferraz, et al. (1997), visam aumentar a capacidade de resposta das empresas diante dos desafios impostos pela economia. Entretanto, se observa que esses programas não vêm atendendo muitos dos produtores do município de Jaru, visto que, na avaliação dos programas de incentivo à produção de leite, estes foram considerados muito baixos. Ressalta-se ainda que $31 \%$ dos produtores desse município não têm conhecimento dos programas desenvolvidos na região e outros $54 \%$ avaliam como regular esses programas.

Quanto à assistência técnica, esse fator também apresenta nível baixo de competitividade dentre os produtores do município de Jaru, visto que $46 \%$ dos produtores entrevistados não vêm recebendo nenhum tipo de assistência para a produção de leite.

Além disso, observa-se na Figura 4 que o nível da avaliação dos produtores quanto à assistência técnica recebida também é baixo, no qual se destaca que $37 \%$ dos produtores dizem que a assistência técnica recebida atende parcialmente às expectativas. Esse aspecto corrobora com as afirmações de Nantes e Scarpelli (2009), para os quais a assistência técnica no Brasil, apesar de estar disponível para grande parte dos produtores rurais, é incapaz de atender às necessidades do agricultor, pois nem sempre são compreendidas ou implementadas devido às condições de cada produtor.

Na pesquisa de campo observou-se ainda que tanto os programas de incentivo como a assistência técnica à produção primária de leite no município de Jaru estão mais presentes entre os produtores que estão organizados em cooperativas ou associação, ou mesmo realizando atividades de forma coletiva. No entanto, observa-se na Figura 4 que ainda é baixo o nível de organização dos produtores de leite de Jaru em cooperativa, associações ou mesmo em ações coletivas, enquanto no município de Patos de Minas a avaliação dos produtores quanto à forma de organização é regular.

Outro fator estrutural de competitividade importante de se destacar diz respeito aos incentivos das indústrias de laticínios à produção primária, pois segundo destaca Ferraz et al. (1997), a formação de amplas parcerias entre produtores, fornecedores e clientes vem sendo uma opção nas indústrias competitivas, pois visa criar condições estruturais adequadas para o incremento da competitividade de todos os elos da cadeia produtiva, uma vez que a competição não ocorre mais no âmbito da firma, mas no âmbito da cadeia produtiva.

Nessa perspectiva, é fundamental para o produtor criar uma relação de parceria com a indústria, visto que a consolidação na indústria de laticínios a torna mais exigente com o produtor, principalmente quanto à qualidade da matéria-prima e práticas sustentáveis no processo de produção. Em vista disso, se observou na pesquisa algumas ações de parceria entre as indústrias e os produtores, sobretudo no que tange também ao atendimento das exigências da Instrução Normativa 51, que obriga os produtores rurais armazenar o leite in natura nos tanques de resfriamento para fornecerem às indústrias. Entretanto, a realização de parceria entre os produtores e indústrias de laticínios se encontra em um nível muito baixo no município de Jaru, sendo ainda incipiente essa prática no município.

Em Patos de Minas, por sua vez, apesar de também ser baixo o nível de parcerias entre indústrias e produtores, essa prática encontra-se em um nível acima de Jaru, pois além de fornecerem tanques aos produtores a indústria ainda presta assistência técnica e, segundo alguns produtores, oferece ainda a garantia de um bom preço pelo produto.

Ainda em relação à consolidação das indústrias de laticínios no Brasil, em que as empresas 
buscam maior poder de mercado, redução dos custos de transação, uma escala de produção que possibilite maior competitividade internacional, observa-se que em vista desses fatores os laticínios vêm praticando o pagamento de valores diferenciados pela qualidade e quantidade do leite captado. Esse pagamento diferenciado destaca-se bem no município de Patos de Minas, avaliado como muito alto o nível desse fator. Em Jaru, no entanto, ainda é baixo o uso desse recurso pelas indústrias para exigirem a produção em maior quantidade e melhor qualidade.

Em relação às políticas de crédito aos produtores rurais, consideradas como um fator determinante de competitividade sistêmico da produção de leite, segundo Nantes e Scarpelli (2009), este ainda não atinge seus objetivos, ou seja, são insuficientes, burocráticos quanto à concessão, com alta taxa de juros e condições de pagamento inadequado, não atendendo, assim, de forma eficiente a muitos pequenos e médios produtores rurais. No entanto, segundo a pesquisa realizada, observa-se que, segundo a avaliação dos produtores do município de Jaru, o acesso ao financiamento apresenta nível regular de competitividade, enquanto as taxas de juros encontram-se num nível alto. Já segundo os produtores de Patos de Minas, o acesso ao financiamento apresenta-se em nível alto e as taxas e juros em nível muito alto.

Nesse aspecto ressalta-se ainda que dentre os produtores entrevistados, $40 \%$ de Patos de Minas utilizaram recursos de financiamento para investirem na produção, enquanto apenas $16 \%$ dos produtores de Jaru se utilizaram de fontes de financiamento para investimento na produção nos três últimos anos. Contudo, em relação à capacidade de expansão da produção, o nível é regular em ambos os municípios pesquisados, considerando para essa análise o interesse de expansão pelos produtores e os investimentos realizados.

No que se refere às atividades de controle da produção, essas apresentam nível muito baixo dentre os produtores de Jaru, que realizam pouco ou nenhum controle das atividades relacionadas à gestão da produção, enquanto em Patos de Minas esse nível foi avaliado como baixo. Observa-se que segundo Nantes e Scarpelli (2009) a gestão na produção rural encontra seu primeiro obstáculo na própria cultura do produtor, em que a baixa prioridade quanto aos aspectos gerenciais é constante na agropecuária nacional.

No que tange aos fatores sistêmicos infraestruturais, têm destaque no município de Jaru a disponibilidade de energia elétrica, que atende $99 \%$ dos produtores entrevistados, apresentando assim nível muito alto, assim como no município de Patos de Minas. Já no que se refere à infraestrutura de comunicação, Jaru apresenta nível de competitividade superior ao de Patos de Minas, visto que há a disponibilidade e acesso ao sistema de telecomunicação a 93\% dos produtores de Jaru, além do acesso à internet por $27 \%$ dos produtores, apresentando assim um nível alto de competitividade nesse fator.

Quanto à infraestrutura viária, no entanto, ainda é considerável precário o acesso a algumas propriedades rurais em Jaru. Desse modo, dentre as avaliações dos produtores de Jaru, o nível desse fator é considerado regular, enquanto em Patos de Minas é alto.

Portanto, segundo a análise apresentada, são diversos fatores que inferem no nível de competitividade do segmento da produção primária da cadeia produtiva de leite. Ao se verificar a média dos 32 (trinta e dois) fatores de competitividade avaliados em uma mesma base de cálculo, segundo mostra a Figura 5, observa-se que a produção de leite em Jaru-RO apresenta-se o nível de competitividade de 4,19, ou seja regular, enquanto em Patos de Minas-MG apresenta um nível de competitividade de 6,23, considerada como alta.

Considerado como alto no nível de competitividade da produção de leite, o município de Patos de Minas apresenta destaque nos fatores de competitividade como a produção de leite, em especial no período da seca, na produtividade do rebanho e na renda bruta do produtor com esta atividade. As principais variáveis observadas que contribuem para a performance no nível de produção desse município estão relacionadas principalmente ao alto nível do rebanho especializado para a produção, alto nível de suplementação alimentar, sobretudo no período da seca, além dos equipamentos que integram o nível de tecnologia empregados na produção de leite desse município.

Nota-se que outros fatores se destacam e vêm contribuindo para o nível elevado de competitividade da produção de Patos de Minas como, por exemplo, o preço do leite recebido pelos produtores; as exigências da indústria por meio do pagamento de valores diferenciados pela qualidade e quantidade do produto; e, a política de crédito para os produtores rurais.

A produção de leite no município de Jaru, por sua vez, apesar de se destacar como o principal 
produtor de leite de Rondônia e o $20^{\circ}$ produtor de leite do Brasil apresenta, conforme apresentado, um nível de competitividade regular. Pode-se dizer que isso ocorre em virtude de ainda serem incipientes muitos fatores determinantes de competitividade desse segmento.

De acordo com os dados apresentados, a produção de Jaru no período das águas é considerada alta. Contudo, segundo é apresentado na pesquisa e que corrobora as afirmações de Paes de Souza (2006), um dos problemas da pecuária de leite do município, assim como de todo o Estado, está relacionado a pouca especialização do rebanho para a produção de leite e a baixa frequência de utilização de suplementos alimentares pelos produtores.

Esses fatores refletem diretamente na baixa produtividade média do rebanho de Jaru, que apesar de ser superior à média do Estado, ainda assim é muito baixa quando comparada ao município de Patos de Minas. Observou-se ainda na pesquisa que mesmo nas propriedades identificadas na pesquisa que dispõem de rebanhos geneticamente qualificados, ocorre baixa produtividade do rebanho, o que pode ser associado possivelmente à inadequação do sistema de produção.

Destaca-se ainda a baixa especialização dos produtores, que também apresentam baixo nível de capacitação e especialização na produção de leite, quer seja pelo baixo grau de instrução quer seja pela falta de interesse desses produtores em se especializarem nessa atividade. Em virtude da baixa especialização, muitos produtores não percebem que as adoções de algumas técnicas simples e de tecnologias na produção podem aumentar gradativamente o rendimento de seus empreendimentos, obterem maior qualidade do produto, e consequente incremento na rentabilidade do negócio.

Por fim, observou-se na pesquisa que muitos dos fatores estruturais e sistêmicos que poderiam contribuir para o desenvolvimento desse segmento da produção de leite no município de Jaru-RO também apresentam baixo nível de competitividade, como os programas de incentivo, a assistência técnica, ações cooperadas entre os produtores e parcerias com a indústria.

Em vista disso, pode-se considerar que o índice regular de competitividade apresentado na produção primária de leite em Jaru não é de responsabilidade exclusiva dos produtores rurais, mas da dinâmica deste setor da região e do sistema produtivo como um todo, cujos fatores também atuam como determinantes de competitividade, segundo afirma Ferraz, et al (1997). Ou seja, há ainda diversas deficiências relacionas também aos outros segmentos da cadeia produtiva e dos demais setores que dão suporte a essa cadeia, os quais encontram obstáculos para dinamização deste setor. Esses fatores podem estar relacionados à baixa concorrência dos produtos lácteos em Rondônia com produtos de outras regiões.

Guardada as devidas proporções das diferenças climáticas ente os municípios pesquisados e da tradição do Estado de Minas Gerais na produção de leite, o município de Patos de Minas, ao contrário de Jaru, possui na região um o sistema produtivo com maior concorrência e mais exigente, o que faz com que os produtores desse município busquem atender as exigências das indústrias e dos consumidores.

Em Jaru, por sua vez, observa-se que há uma baixa dinâmica do setor na região, em que mesmo havendo certa concorrência entre as indústrias de laticínios do setor, estas não dinamizam a concorrência na produção primária tal como ocorre em Patos de Minas, refletindo assim no baixo nível de especialização dos produtores de leite e, consequentemente, na baixa eficiência da produção de leite na região.

\section{5 conclusões}

No estudo realizado, alcançou-se o objetivo proposto na pesquisa, visto que com base na análise de 32 fatores de competitividade o resultado da pesquisa demonstrou que o município de Jaru possui um nível de competitividade regular, enquanto o município de Patos de Minas apresenta um nível de competitividade considerado alto. O resultado da análise demonstra ainda que muitos dos fatores determinantes de competitividade internos, estruturais e sistêmicos da produção de leite de Jaru-RO ainda apresentam baixo nível de competitividade, se comparados a outros produtores com características semelhantes.

Embora seja uma atividade de maior expressividade na composição da renda familiar dos produtores que atuam na pecuária de leite, bem como na própria economia regional, a produção de leite em Jaru-RO ainda é uma atividade pouco tecnificada. Com rebanho de baixo potencial genético na produção de leite; deficiência na alimentação suplementar do rebanho no período da seca; baixa capacitação dos produtores; e, muito baixa visão e adoção de instrumentos de gestão da atividade, a produção de leite nesse município resulta, de modo geral, em baixo desempenho. 
Tal situação se acentua quando comparada ao desempenho da produção de leite de Patos de Minas, que apresenta melhores níveis de tecnologia empregada na produção, rebanho especializado para a pecuária leiteira, e em vista disso apresenta melhor desempenho na produção de leite e alto índice de produtividade.

De forma complementar, a avaliação dos fatores externos ao empreendimento no município de Jaru, os quais são relevantes para o sucesso competitivo desse segmento, tais como as formas de organização dos produtores, programas de incentivo, assistência técnica, exigências do mercado e parceria com outros agentes da cadeia produtiva, é considerada baixa no nível de competitividade.

Logo, considerando que cada empreendimento é parte integrante de um sistema econômico que favorece ou restringe a efetivação do seu potencial competitivo, verificou-se na pesquisa que no caso da produção de leite em Jaru há uma baixa dinâmica do setor na região, e mesmo havendo certa concorrência entre as indústrias de laticínios do setor, estas não dinamizam a concorrência na produção primária tal como ocorre em Patos de Minas.

Assim, na perspectiva de aprimoramento desse sistema, a cadeia produtiva de leite em Jaru necessita desenvolver vários fatores que inferem nas vantagens competitivas desse segmento, em vista da obtenção de um melhor desempenho na produção e no atendimento às exigências cada vez maiores do mercado consumidor. Para isso, considerando que a competitividade não se restringe apenas ao nível da empresa, mas, sim, no âmbito de toda cadeia produtiva, é necessário um esforço conjunto tanto dos produtores como dos outros elos da cadeia produtiva, além do ambiente organizacional, como instituições de pesquisa e órgãos públicas, visando elevar o nível de competitividade dessa cadeia produtiva na região.

\section{REFERÊNCIAS}

ALVES, Simone; FERREIRA, Nayara. Medida da competitividade do destino Brasil: uma aplicação do Índice de Competitividade Turística do WEF 2008. Observatório de Inovação do Turismo - Revista Acadêmica Mar 2009: 1-26.

ALVIM, Rodrigo Sant'Anna. Oportunidade para a produção de leite no Brasil. Disponível em: <http://www. cna.org.br> Acesso em: 16 mar.2009.

ARAÚJO, Massilon J. Fundamentos de Agronegócios. 2th ed. São Paulo: Atlas, 2009.

CALDEIRA, Adilson; SIQUEIRA, Moema Miranda. Competitividade e desenvolvimento sustentável na visão de gestores. Revista Economia \& Gestão - v. 09, n. 21, set./dez. 2009.

CALLADO, A. A. C.; CALLADO, A. L. C. Gestão de custos rurais: comparando práticas entre distintos polos de produção agroindustriais do estado de Pernambuco. In. Revista Contemporânea de Economia e Gestão, v. 7, n. 2, p. 65-74, 2009.

EMBRAPA. Empresa Brasileira de Pesquisa Agropecuária. Produtividade e sustentabilidade da atividade leiteira em debate. Embrapa, 2009. Disponível em <http://www.cpafro.embrapa.br.>. Acesso em 22 de mai. 2011.

FERRAZ, João Carlos; KUPFER, David, HAGUENAUER, Lia. Made in Brazil: desafios competitivos para a indústria. Rio de Janeiro: Editora Campus, 1997.

GALINARI, Rangel; CAMPOS, Bruno; LEMOS, Mauro Borges; SANTOS, Fabiana; BIAZI, Elenice. Tecnologia, especialização regional e produtividade: um estudo da pecuária leiteira em Minas Gerais. In. Anais do X Seminário sobre a Economia Mineira: Belo Horizonte, 2002.

GOMES, Sebastião Teixeira. Diagnóstico da pecuária leiteira do Estado de Minas Gerais em 2005: relatório de pesquisa. Belo Horizonte: FAEMG, 2006. 
IBGE. Instituto Brasileiro de Geografia e Estatística. Pesquisa Pecuária Municipal 2008. Rio de Janeiro: IBGE, 2009. Disponível em: <www.ibge.gov.br>. Acesso em 24 Nov. 2010.

IBGE. Instituto Brasileiro de Geografia e Estatística. Produção da Pecuária Municipal 2009. Rio de Janeiro, v. 37, p. 1-55, 2010. Disponível em <htpp://www.ibge.gov.br>. Acesso em jun 2011.

KUPFER, David. Padrões de Concorrência e Competitividade. Rio de Janeiro: IEI/UFRJ, 1991. Texto para discussão $\mathrm{n}^{\circ} 265$.

LIMA, Giovani Neves. Segmento de serviços industriais do pólo petroquímico de Camaçari: um estudo sobre a competitividade. Dissertação (Mestrado Profissional em Administração) - Escola de Administração. Universidade Federal da Bahia, Salvador. 2007.

NANTES, José Flávio Diniz; SCARPELLI, Moarcir. Elementos de gestão na produção rural. In. BATALHA, Mário Otávio (cood.). Gestão Agroindustrial. GEPAI: Grupo de Estudos e pesquisas agroindustriais. 3th ed. Vol. 1. São Paulo: Atlas, 2009.

NOGUEIRA, Maurício Palma; TURCO, Cristiane de Paula; PAIVA, Hélio Afonso Braba; LOPES, Maíra Bacha. Produção Leiteira. In. Estratégia para o Leite no Brasil. CONSOLI, Matheus Alberto; NEVES, Marcos Fava (cood.). Atlas: São Paulo, 2006. p. 90-118.

PAES DE SOUZA, Mariluce. Estudos diagnósticos de aglomerações / Arranjo produtivo local do leite: Região central do estado de Rondônia In. ADA - Agência de Desenvolvimento da Amazônia. Plano de desenvolvimento sustentável da Amazônia legal. Universidade Federal do Pará, Organização dos Estados Americanos. Belém: ADA, 2006.

PAES DE SOUZA, Mariluce. Governança no agronegócio: enfoque na cadeia produtiva do leite. Porto Velho: Edufro, 2007.

PORTER. Michael E. A Vantagem Competitiva das Nações. Rio de Janeiro: Campus, 1993.

POSSAS, Mário Luiz. Competitividade: Fatores Sistêmicos e Política Industrial - implicações para o Brasil. In. Estratégias Empresariais na Indústria Brasileira: Discutindo Mudanças. CASTRO, Antônio Barros (org.) Rio de Janeiro: Forense Universitária, 1996.

QUEIROZ, Lucia Maria Aquino de. A gestão pública e a competitividade de cidades turísticas: a experiência da cidade de Salvador. Tese de doutorado. Universidade de Barcelona. 2005

RICHARDSON, Roberto Jarry. Pesquisa social: métodos e técnicas. 3. ed. São Paulo: Atlas, 2007.

SCHEIDT, Ademar Silva Junior. A Força Competitiva dos Supermercados como Compradores de Produtos Lácteos da Indústria de Rondônia. Dissertação (Mestrado) - Programa de Pós-Graduação Mestrado em Administração - Universidade Federal de Rondônia, Porto Velho, Rondônia, 2008.

SILVA NETO, Romeu; PIZZOLATO, Nélio Domingues. Uma metodologia para a análise da competitividade sistêmica empresarial. In. XXI ENEGEP, 17-19 outubro, Salvador, 2001.

SILVA, Ermes Medeiros da; SILVA, Elio Medeiros da; GONÇALVES, Valter; MUROLO, Afrânio Carlos. Estatística para os cursos de: economia, administração e ciências contábeis. 2. Ed São Paulo: Atlas, 1997.

TAVARES, P., KRETZER, J., MEDEIROS, N.. Economia Neoschumpeteriana: expoentes evolucionários e desafios endógenos da indústria brasileira. In. Revista Economia Ensaios, América do Norte, 20, jan. 2009.

TEIXEIRA, Francisco. Estruturas de mercado e competitividade industrial: breve referencial teórico. In. Bahia Análise e Dados. V. 14, n. 4, p. 745-754, mar. 2005 